This is an electronic reprint of the original article. This reprint may differ from the original in pagination and typographic detail.

Please cite the original version: Henriksson, K. ; Ruoslahti, H. \& Hyttinen, K. (2018) Opportunities for Strategic Public Relations - Evaluation of International Research and Innovation Project Dissemination. In Sarah Bowman, Adrian Crookes, Stefania Romenti, Øyvind Ihlen (eds.) Public Relations and the Power of Creativity (Advances in Public Relations and Communication Management, Volume 3) Emerald Publishing Limited, pp.197 - 214.

doi: 10.1108/S2398-391420180000003012

URL: https://doi.org/10.1108/S2398-391420180000003012

This is an Author Accepted Manuscript version of the original article. 
in Sarah Bowman, Adrian Crookes, Stefania Romenti, Øyvind Ihlen (ed.) Public Relations and the Power of Creativity (Advances in Public Relations and Communication Management, Volume 3, Emerald

Publishing Limited, pp.197 - 214.

\title{
Opportunities for Strategic Public Relations - Evaluation of International Research and Innovation Project Dissemination
}

\begin{abstract}
European industry, academia, and potential end users for future solutions are widely involved in applying for European Union (EU) funding of research and innovation and implementation of the projects. Funding instrument requirements emphasize the influence of skills and knowhow of these project consortia professionals. This chapter proposes a co-creative model for communication and dissemination, or project PR, based on the experiences of both planning and coordinating dissemination activities of three EU funded projects. Multidisciplinary international project PR offers strategic opportunities for PR professionals.

The model employs the co-creation methods based on the pedagogical model called Learning by Developing (Laurea, 2011). In addition to the pedagogical model, the proposed conceptualization of co-creation for public relations and dissemination utilizes a media evaluation framework, which is adapted from Vos \& Schoemaker's model (2004), combining elements of both balanced scorecard and quality management.

The findings demonstrate that commitment and active participation of end user groups in the early stage of the project are needed for successful dissemination, which should be supported by each partner's PR actions and networks. The dissemination process should start when the project begins, be ongoing, even extending to beyond the project. Dissemination is an expanding process, and it requires facilitation that supports PR and the engagement of key stakeholders. The European Commission can gain from modernized PR and dissemination activities, and from as many end users as possible adopting new innovations, which generate more business possibilities for the industry, and further research projects for the academia.
\end{abstract}

Key words: Public relations, strategic communication, dissemination, communication, co-creation, Learning by Developing, evaluation

\section{Introduction}

European industry, academia, and potential end users for future solutions are widely involved in applying for EU funding for research and innovation projects. The requirements for efficient dissemination and exploitation set by the funding instruments, such as the European Commission's Horizon 2020, are increasing. Requirements emphasize the influence of the projects and the skills and knowhow of the project consortia, as Di Cagno et al. (2014, p. 853) write: "given the large and increasing amount of European resources devoted to promote scientific co-operations among countries, it is important trying to assess their actual technological and economic impact." One objective of funded projects is to expand the benefit of results in the European Union. The dissemination of Horizon 2020 projects is defined as public disclosure of results by all appropriate means (European IPR Helpdesk, 2014), and the overall purpose of dissemination includes achieving scientific excellence. Project dissemination can be looked upon as Public Relations (PR), and its actors as PR practitioners.

One example is the FP7 project topic SEC-2012.3.4-6 Enhancing the workflow and functionalities of Automated Border Control (ABC) gates - Integration Project (European Commission, 2011). This 
in Sarah Bowman, Adrian Crookes, Stefania Romenti, Øyvind Ihlen (ed.) Public Relations and the Power of Creativity (Advances in Public Relations and Communication Management, Volume 3, Emerald Publishing Limited, pp.197 - 214.

project is expected to contribute towards a more harmonized common European approach in its field, automated border control. Funding instruments often require the active participation of end users in both research by project consortia and as targets for dissemination. In the case of the Automated Border Control (ABC) gates project, "Institutions of several Member States are expected to be involved in the case of large-scale pilot project involving different border crossing points and all types of borders" (European Commission, 2011, p. 43). Another example is the H2020 call BES-2014-12 on border and external security for improvement of conflict prevention and peacebuilding capabilities of the EU. This call looked for a project that can deliver enhanced activities of coordination and support with strong engagement of key stakeholders and end users. The resulting project, Improving the Effectiveness of Capabilities in EU Conflict Prevention (IECEU), was funded under this call and aimed to meet the requirements through active dissemination methodology and PR activities.

Funded projects are joint ventures built on trust and common goals. Basically, partners form a consortium with a joint interest for development and / or research which they carry out together. In light of this common interest, it is important to identify sufficient ways of communication and dissemination to satisfy the requirements of the funding instrument, and to meet the aims and agendas of the various stakeholders. The ways to plan and implement dissemination activities are many, so it is important that project consortia have clear plans, which are in line with the project objectives, carry them out actively, and react to any feedback that they receive.

There are clear duties set for partners regarding external communication and dissemination activities by the funding instruments. Project partner actors, who are not used to working with actual external communication and dissemination duties, can find these duties unnecessary or unfamiliar. Some partners outsource these PR activities, and some even end up avoiding the activities as much as possible.

Then there are partners who actively promote the project, disseminate and communicate externally to the general public, the academia, and various stakeholders. Projects, where every partner does not actively participate in PR activities throughout the whole project lifecycle, do not necessarily meet the criteria for funding. Although the projects are based on trust and partners' mutual agreement on joint ventures, the case of not participating in daily communication and dissemination makes the project and its results weaker than in those projects where there are shared ways of working.

This chapter proposes a modern co-creative model for PR activities and dissemination based on theoretical approaches on communication quality, and practical experiences gained in planning and coordinating communication and dissemination activities of three EU funded projects. The results section discusses some strategic opportunities for the creative use of Public Relations to mitigate critical challenges in innovation projects. The research question is: how can external communication and dissemination, i.e. project PR, be carried out to efficiently address the requirements of the funding instrument and benefit the project?

\section{Project Communication and Dissemination}

The European Commission (2014) outlines that communication about European research projects should aim at demonstrating the ways in, which "European collaboration has achieved more than have otherwise been possible" (p. 1) and how its outcomes are both relevant to the lives of us Europeans. Creative people best achieve desired outcomes, when objectives are clearly defined. For efficient strategic communication it is key to clarify messages and choose the appropriate media according to the target audience. 
in Sarah Bowman, Adrian Crookes, Stefania Romenti, Øyvind Ihlen (ed.) Public Relations and the Power of Creativity (Advances in Public Relations and Communication Management, Volume 3, Emerald Publishing Limited, pp.197 - 214.

Efficient and timely communication of project activities ensures the success of a project and is a core interest of projects (GAP D7.1, 2016), both during, and even beyond, the lifespan of the project. A dissemination plan will provide an overall framework to coordinate and manage communication during the implementation of a project. Dissemination in projects can be divided into two different key groups; dissemination material and dissemination activities. (Hyttinen, 2017). Different communication platforms and tools are developed to ensure a wide reach of various stakeholders and end users (IECEU, 2015). EU research and innovation funding and project dissemination should pay special attention to showing how collaboration has achieved more than would otherwise have been possible, showing how the outcomes are relevant, and making better use of the results among decision-makers, industry or academia (Hyttinen, 2017).

To make best use of project results, they should be taken up by the end users, policy-makers, industry, and the scientific community (European Commission, 2014). A project itself functions as an organization with an action plan, vision and mission, as well as a clear budget and time plan. The project's main actor organizations are partners by contract. Partners who work together in teams generate new knowledge and skills, resulting in innovations. In the action model Learning by Developing ( $\mathrm{LbD}$ ), projects function as a learning environment, while they also create new knowledge for innovations. LbD has five dimensions, which form the learning / working environment: authenticity, experiential nature, partnership, creativity, and research orientation (Laurea, 2011). A project is an authentic environment; the case is real. Partners operate in partnership with the stakeholders and end users, and they employ an experiential approach and are creative, while they carry out research and develop new joint products to meet their aims. The value that is created in a joint activity is generated by their shared experiences and the partnership with stakeholders, in an authentic manner.

In projects, partners co-create with stakeholders, and their shared experiences are vital for dissemination activities. With active co-creation, new competencies arise from social interaction and knowledge sharing, as shared competence of communities and organized groups of experts and professionals (Pirinen, 2015). The value of this shared competence is key to receiving funding for joint projects. Customers and users are active participants in value co-creation to design personalised experiences, services, and products (Allen et al., 2009). Pirinen (2015) concludes that building useful knowledge and innovation processes is "increasingly complex, multidisciplinary, trust-based, cocreated, path-depended, and globalized" (p. 323). Frow et al. (2015) seek to provide an understanding on how co-creation can improve resource integration in complex settings and offer a framework for organizations to design and manage co-creation processes.

Project experts sometimes find themselves in uncomfortable positions when facing the need to communicate and disseminate in a professional way in projects. These experts might have a basic understanding of strategic communication. Wilson et al. (2010) find that the identified theoretical research dissemination frameworks are converging and still overly focus on "linear messengerreceiver models and do not draw upon other aspects of communication theory" (p. 14); they note that the key to successful dissemination is dependent on the need to interact with end users. Some traditional ways of sharing knowledge and interacting with end users have been press releases, seminars and conferences. At present, modern electronic platforms provide secure possibilities for co-creative knowledge sharing and learning online (Davis Cross, 2015).

Public relations is strategic communication, and different organizations use it to establish and maintain symbiotic relationships with relevant and increasingly culturally diverse publics (Sriramesh et al., 2017). Falkenheimer \& Heide (2014) see PR as one of three fields under strategic communication, the other two being organizational communication, and marketing communication. They note that PR concentrates on activities and communication where stakeholders or publics can 
in Sarah Bowman, Adrian Crookes, Stefania Romenti, Øyvind Ihlen (ed.) Public Relations and the Power of Creativity (Advances in Public Relations and Communication Management, Volume 3, Emerald Publishing Limited, pp.197 - 214.

be treated as segments. This also applies to innovation projects, as dissemination is described as the public disclosure of the results of the project in any medium.

According to the European Commission (2017), the key aim for dissemination is to make research results known to different stakeholder groups, such as academia, industry, professional end user organizations, and policymakers in a planned and targeted way. The Commission (European Commission, 2016) makes a clear difference between dissemination, exploitation, and communication, the concepts of which are defined as follows.

The Commission likens dissemination activities to a shopkeeper attracting customers. Therefore, one should always consider a funded project as a fixed-duration business with all the duties, aims, objectives and tasks. A process of promotion and awareness-raising from the beginning of a project can make its research results known to research peers, industrial and other commercial actors, and policymakers, in targeted ways, enabling them to exploit the results in their own work.

The Commission describes exploitation as "the use of the results during and after the project's implementation. It can be for commercial purposes but also for improving policies, and for tackling economic and societal problems" (European Commission, 2016). Exploitation, thus, spreads the findings and utilizes them for the benefit of a larger geographical area. Furthermore, if the benefits can be employed in a variety of fields of interest, in addition to the field of the project, it makes the results of exploitation activities more valuable.

Communication refers to the project

taking strategic and targeted measures for promoting the action itself and its results to a multitude of audiences, including the media and the public, and possibly engaging in a two-way exchange. The aim is to reach out to society as a whole and in particular to some specific audiences while demonstrating how EU funding contributes to tackling societal challenges. European Commission, 2016

It is interesting to note that one-way communication still seems to be the main direction and scope for projects funded by the European Union. The option of engaging in a two-way exchange is voluntary. However, to make an impact, two-way communication has the potential of being more efficient than one-way. To ensure improved quality, research is needed to develop professionalism in the management of communication, and best practices should be actively shared (Vos \& Schoemaker, 2004). This can be extended to external communication and dissemination in funded projects. Communication in a project will initially start when collaborators start working towards common goals, and information is input to serve as a basis for the project, and the development and innovation work within. A project can, for example, interview stakeholders and create scenarios that input information to the project and guide the co-creation of knowledge and innovation (Ruoslahti, 2017).

To guide the practical work of a project network, information is shared and communicated between project members, partners and other stakeholders. In many funded projects, work packages are distributed between partners, and solitude work by one partner at a time is carried out, making shared work activities sometimes difficult. Communication takes place all the time, whenever one acts or does something. If partners work as a team on different tasks and work packages, it would make all the duties of communication, dissemination and exploitation much easier for all. Vos (2015) notes that "communication can contribute to a company's economic and social goals by seeking to enhance its corporate reputation, positioning of products and services, and internal consistency" (p.64). Key processes in doing this include monitoring stakeholder perceptions, arranging interaction with them and facilitating network exchange within the organization (Vos and Schoemaker, 2011). 
in Sarah Bowman, Adrian Crookes, Stefania Romenti, Øyvind Ihlen (ed.) Public Relations and the Power of Creativity (Advances in Public Relations and Communication Management, Volume 3, Emerald Publishing Limited, pp.197 - 214.

These same principles can be applied to projects as well as established organizations. Communication plays a role in a project's economic and social goals by seeking to enhance the reputation of the project in question, positioning of its outcomes and deliverables, and internal consistency. In their strategy map for communication, Vos \& Schoemaker (2011) look at communication on four different levels: organizational goals, communication goals, key processes, and learning and growth.

On the first level, organizational goals, or in this case common goals for a project network, are added value and social acceptance. On the second level, communication goals, are reputation and being rooted in the social environment; project outcomes are positioned as products or services, and coherence as the organization of the project network. On the third level, key processes include monitoring stakeholder perception, examining communication via news, social media, etc., and facilitation of network exchange. These key processes are identifiable in the dissemination and communication plans for all three projects ABC4EU, IECEU, and GAP. On the fourth level, learning and growth, one can find communication planning and research, and knowledge management and training. The focus of this chapter is on this level.

Projects are required by the EU funding instruments to openly disseminate the results of the project for efficient exploitation. In past experiences this has been done towards the end of the project, which poses a serious problem both to the consortium and the funding instrument. Criteria for funding may not be met in those cases. This should change. One can keep in mind the Commission's simile of a shopkeeper and the need to attract the shop's customers. End users and other stakeholders should become involved in the dissemination process already from the start of the project. The dissemination process, and its evaluation, which are proposed in this chapter, are designed around this principle.

\section{Three Projects Examined}

This chapter explores the planning and evaluation of external communication and dissemination in three funded project cases. Project ABC4EU will have run its course during the year 2018, whereas IECEU and Gaming for Peace started their activities in the fall of 2015 and 2016, respectively. This chapter suggests that a framework with strengthened co-creation as a method can intensify external communication and dissemination in funded projects. The experiences of the three funded projects partially present the co-creation concept of this chapter; the authors have developed the idea further to conceptualize the planning, process, and evaluation of the activities. As an example, the dissemination process for ABC4EU is illustrated in Figure 1 (ABC4EU, 2012). The main aim of this process is to engage a community of potential users from the very start of the project to ensure not only efficient dissemination, but also the continuous and active input of end user experts. This model of co-creation can create opportunities to link stakeholder collaboration for creativity and innovation. PR skills and active facilitation become emphasized in this approach. 
in Sarah Bowman, Adrian Crookes, Stefania Romenti, Øyvind Ihlen (ed.) Public Relations and the Power of Creativity (Advances in Public Relations and Communication Management, Volume 3, Emerald Publishing Limited, pp.197 - 214.

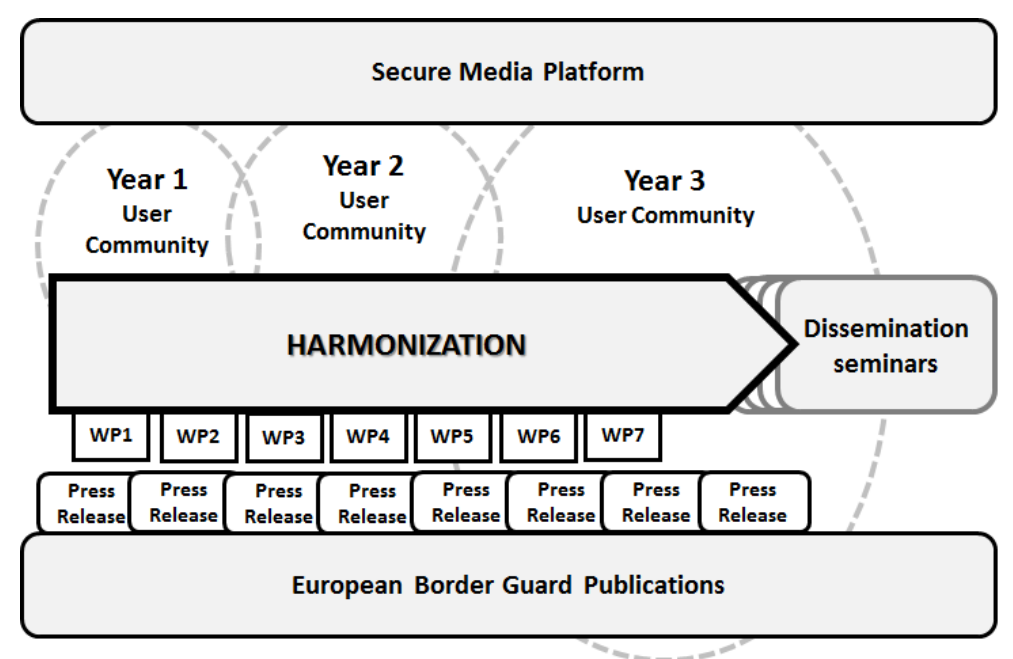

Figure 1: Communication and dissemination model for project $\mathrm{ABC} 4 \mathrm{EU}$

$\mathrm{ABC}$ Gates for Europe $-\mathrm{ABC} 4 \mathrm{EU}$ is a project with 17 partners. The main objective of the project is to "focus in the need for harmonisation in the design and operational features of ABC Gates, considering specially the full exploitation of the EU second generation passports and other accepted travel documents" (ABC4EU, 2012, p.4). There are nine work packages, with WP7 Dissemination \& Exploitation focusing on external communication and dissemination. In the Framework Programme FP7 project $A B C 4 E U$, dissemination, as seen in figure 1, was planned to begin from the very start of year one (Y1) of the project (ABC4EU, 2014). The aim has been to grow the User Community in number and keep end users, industry, and academia actively involved with interactive participation on a secure social media platform. The key to get end users involved in ongoing communication activities in a project where the end users receive no funding for their efforts is to find their ultimate benefit and smaller benefits during the project lifecycle. Interactive participation can enable the creation and growth of an end user community, and this community can in turn serve as a basis for two-way communication with end user organizations and professionals. In addition, press releases, publications and articles have been used.

The second examined project IECEU (Improving the Effectiveness of Capabilities in EU conflict prevention) was implemented from 2015 to 2018 . The dissemination methodology was a combination of defined end user groups and the use of different dissemination tools and activities. The overall comprehensive dissemination methodology included the involvement of both EU and other international organizations, respective countries, universities, as well as other projects and partners, and the use of a secured internal website and external online tools for dissemination, discussion, and media-based learning (IECEU D8.1, 2015). The aim of the dissemination focused on making better use of the results among key stakeholders. (Hyttinen, 2017). The use of technology in dissemination and communication was strongly addressed in this project implementation.

The third funded project which this chapter discusses is the Horizon 2020 project Gaming for Peace, GAP, which is based on the notion that operationally critical soft skills, communication, cooperation, and negotiation, are often not emphasized enough. The Project GAP proposes to fill this training gap, by embedding, into a gaming environment, a "base curriculum of soft skills that facilitates coordination and relationship building in an environment of organisational, gender and cultural diversity" (GAP D7.2, 2016, p. 5). The project has fourteen partners. "The communication and dissemination activities are fundamental in order to create project visibility and to reach various target groups" (GAP D7.2, 2016, p. 3). Efficient communication is key to a successful GAP project. 
Henriksson, K., Ruoslahti, H., \& Hyttinen, K.

in Sarah Bowman, Adrian Crookes, Stefania Romenti, Øyvind Ihlen (ed.) Public Relations and the Power of Creativity (Advances in Public Relations and Communication Management, Volume 3, Emerald

Publishing Limited, pp.197 - 214.

\section{Adapted Methodology for Project PR}

This chapter presents a model of co-creation based on the pedagogical model, Learning by Developing (Laurea, 2011). LbD is a way of learning and developing, created for university studies and utilized in project work. A project, in itself, is a learning environment, involving partners, stakeholders, possible clients and end users cooperating with each other in partnership, employing an experiential nature when researching and co-creating something new in an authentic project, all participants learning from each other at the same time. The LbD Guide (2011, p.12) also notes that

A learning environment is also a psychological state. It enables encounters among different participants and interaction that leads to genuine cooperation. The atmosphere is open and respects equality. The working culture is inspiring, supporting creative and finding new ideas. Shortcomings and sidetracks are turned into positive learning experiences. The communication culture is open and respectful. Diversity is a resource for innovation. Partnership fosters responsible collaboration. Learning environments enable joint activities, evaluation and development of personal ways of action based on experiences.

The description above meets the ways of working in a multi-actor cross-border project. The criteria set by the funding instruments are crucial for the planning of external communication and dissemination of funded projects. The consortium needs to include a plan for communication and dissemination with their funding application. This emphasizes the importance of the role of PR, in this case communication and dissemination, for the project. Furthermore, in the planning stage of external communication and dissemination, one needs to look at the whole cycle of external communication and dissemination: plan, act, evaluate, re-plan, act, evaluate, etc. Projects should make sure that PR skills are developed, and that PR professionals jointly facilitate collaboration in co-creation activities. Communication and dissemination technologies require the competences of the people related to a project's knowledge and information sharing. The dissemination technologies which support project collaboration within a consortium as well as among key stakeholders and public audience are: the Web, secured access websites, video conferences, social media, document management and so forth. The selection of the dissemination technology depends on the target group (Juan, 2012. p. 220). The technology and information sharing increase additional competence and professional requirements for experts working with project dissemination.

The proposed framework employs the model of Vos and Schoemaker (2004) that combines elements of both balanced scorecard and quality management to evaluate communication. The evaluation of external communication and dissemination is done by measuring the effectiveness of its activities. The measurement process follows the quality cycle by Juholin, (2010). The first step is to define evaluation aims, the second step is the method and data sets, third, data is collected and analyzed, fourth, results reported, and the final step is re-evaluation and choosing the next steps, so that the cycle may start again. The main aim is to continuously improve the quality of the communication and its value for the organization (Vos, 2015). According to Verčič et al. (2015), finding internationally socialized people to "... work in a cross-cultural setting, and capable of taking international and global public relations practice to a new level ..." (p. 791) is a major challenge. This is also demonstrated in the three projects examined. 
Henriksson, K., Ruoslahti, H., \& Hyttinen, K.

in Sarah Bowman, Adrian Crookes, Stefania Romenti, Øyvind Ihlen (ed.) Public Relations and the Power of Creativity (Advances in Public Relations and Communication Management, Volume 3, Emerald

Publishing Limited, pp.197 - 214.

\subsection{Quality Dimensions}

This section discusses the dimensions of communication quality by Palttala \& Vos (2012, p. 39) and illustrates how these dimensions were linked to the externally funded project domain. These dimensions are A) clarity, B) environment orientation and linkages, C) consistency, D) responsiveness, and E) effectiveness and efficiency. They are summarized in Table 1 below.

\begin{tabular}{|l|l|l|}
\hline \multicolumn{2}{|l|}{ Evaluation targets focus } \\
\begin{tabular}{|l|l|} 
Dimensions of communication \\
quality
\end{tabular} & A. Clarity & $\begin{array}{l}\text { Clarity refers to communicating a } \\
\text { clear profile and with messages } \\
\text { that are distinctive, accessible, } \\
\text { and in clear language }\end{array}$ \\
\cline { 2 - 3 } & $\begin{array}{l}\text { A. Environment orientation and } \\
\text { linkages }\end{array}$ & $\begin{array}{l}\text { Taking into account the internal } \\
\text { and external environment, } \\
\text { networking and media contacts }\end{array}$ \\
\cline { 2 - 3 } & B. Consistency, effectiveness \\
and efficiency & $\begin{array}{l}\text { The communication is coherent, } \\
\text { has a thread that connects the } \\
\text { activities over time and fits the } \\
\text { project }\end{array}$ \\
\cline { 2 - 4 } & C. Responsiveness & $\begin{array}{l}\text { Detect changes through } \\
\text { monitoring and use feedback for } \\
\text { improvement }\end{array}$ \\
\cline { 2 - 3 } & D. Effectiveness and efficiency & $\begin{array}{l}\text { A result- and goal-oriented } \\
\text { communication effort, defining } \\
\text { priorities by using planning, } \\
\text { research and cost-efficient } \\
\text { operations }\end{array}$ \\
\hline
\end{tabular}

Table 1: The dimensions of communication quality (adapted from Vos \& Schoemaker, 2004; Vos 2009)

Palttala and Vos (2012) emphasize that these five dimensions are "the pillars of communication quality" (p. 39), and that they cannot be isolated from each other. They are all linked to and support each other.

\subsection{Domains of Project Communication and Dissemination}

The quality dimensions presented above are applied to various domains in evaluating dissemination activities. For this, the model of Vos and Schoemaker (2004) on organizational communication are adapted to meet the criteria of funded project dissemination. Figure 2 shows the different domains of project communication and dissemination, which are included in the evaluation framework proposed in this chapter. The five domains refer to the areas of project communication and dissemination. 
in Sarah Bowman, Adrian Crookes, Stefania Romenti, Øyvind Ihlen (ed.) Public Relations and the Power of Creativity (Advances in Public Relations and Communication Management, Volume 3, Emerald Publishing Limited, pp.197 - 214.

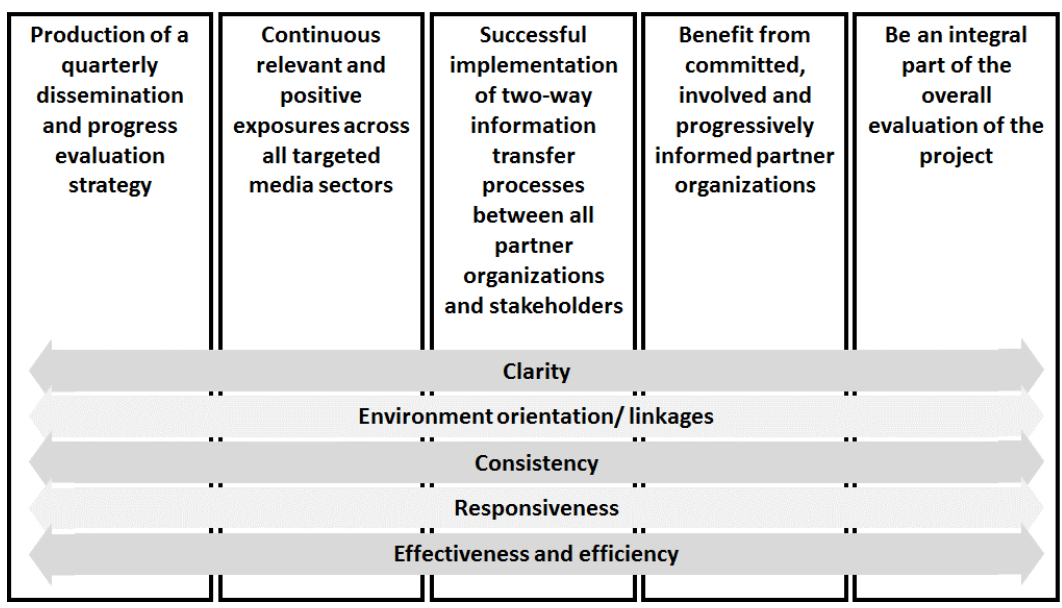

Figure 2: Communication and dissemination evaluation model (partly based on Vos \& Schoemaker, 2004)

The domains are based on the grant agreement (unpublished document) for the project GAP and are thus expected to have a wider bearing. In the project GAP, they were used as a basis for the communications plan of the project (GAP D7.1, 2016). The grant agreements of EU funded projects specify important communication that, consequently, should be reported to the funder. In externally funded projects, dissemination and communication activities should be reported regularly both within the consortium, and to the funding agency. This is done as part of periodic technical reviews, as well as summarized for the duration of the project as part of the final report. Dissemination reporting is due between monthly and every four months' time, throughout the duration of the project implementation.

Some key features of reporting are the dissemination/communication action (e.g. event), date and place, target group, number of people/participants that dissemination was done towards, objective and description, and communication channels/tools used. Dissemination reporting is typically aided by templates, which are prepared based on these key features, and support the data collection from the various consortium partners.

If not paid close attention to, in the planning phase, these templates that gather information from dissemination activities may gather information that is dispersed into different tables, resulting in unlinked incoherent details. Also, it is advisable to remember to include an easy access system to attach written messages and texts to the report template as records of communication and dissemination activities carried out. All partners should report their external communication and dissemination activities regularly, even if there have not been any activities or only a few. Motivating each partner to do their reporting in a timely fashion and generating a routine to examine and document one's own dissemination activities are a way to develop one's own work and find common ground to cooperate with partners.

\subsection{The Evaluation Framework}

For evaluation of project communication and dissemination, the quality dimensions are applied to the communication dimensions. This provides a matrix with various indicators, as shown in Table 2. 
Henriksson, K., Ruoslahti, H., \& Hyttinen, K.

in Sarah Bowman, Adrian Crookes, Stefania Romenti, Øyvind Ihlen (ed.) Public Relations and the Power of Creativity (Advances in Public Relations and Communication Management, Volume 3, Emerald Publishing Limited, pp.197 - 214.

\begin{tabular}{|c|c|c|c|c|c|}
\hline $\begin{array}{l}\text { Quality } \\
\text { dimensions }\end{array}$ & $\begin{array}{l}\text { Quarterly } \\
\text { dissemination and } \\
\text { progress evaluation }\end{array}$ & $\begin{array}{l}\text { Relevant and } \\
\text { positive exposures } \\
\text { across all targeted } \\
\text { media sectors }\end{array}$ & $\begin{array}{l}\text { Successful two-way } \\
\text { information transfer } \\
\text { processes between } \\
\text { project partners and } \\
\text { stakeholders }\end{array}$ & $\begin{array}{l}\text { Committed, involved } \\
\text { and progressively } \\
\text { informed partner } \\
\text { organizations }\end{array}$ & $\begin{array}{l}\text { Adoption of project } \\
\text { processes across } \\
\text { the EU }\end{array}$ \\
\hline Clarity & $\begin{array}{l}\text { Clear positioning of } \\
\text { the project }\end{array}$ & $\begin{array}{l}\text { Clear positioning } \\
\text { across targeted } \\
\text { media sectors }\end{array}$ & $\begin{array}{l}\text { Information to } \\
\text { stakeholders is clear }\end{array}$ & $\begin{array}{l}\text { External communication } \\
\text { vision is clearly defined }\end{array}$ & $\begin{array}{l}\text { Clear positioning of } \\
\text { project processes } \\
\text { across the EU }\end{array}$ \\
\hline $\begin{array}{l}\text { Environment } \\
\text { orientation/ } \\
\text { linkages }\end{array}$ & $\begin{array}{l}\text { Maintain networks } \\
\text { for the project's } \\
\text { reputation }\end{array}$ & $\begin{array}{l}\text { Maintain networks } \\
\text { across targeted } \\
\text { media sectors }\end{array}$ & $\begin{array}{l}\text { Communication } \\
\text { reinforces commitment } \\
\text { and supports two way } \\
\text { information transfer } \\
\text { between partner } \\
\text { organizations and } \\
\text { stakeholders }\end{array}$ & $\begin{array}{l}\text { Internal and external } \\
\text { communication function } \\
\text { is well embedded in all } \\
\text { project work }\end{array}$ & $\begin{array}{l}\text { Communication } \\
\text { supports two way } \\
\text { information transfer } \\
\text { of project processes } \\
\text { across the EU }\end{array}$ \\
\hline Consistency & $\begin{array}{l}\text { Consistency with } \\
\text { other communication }\end{array}$ & $\begin{array}{l}\text { Consistency in } \\
\text { message across } \\
\text { targeted media } \\
\text { sectors }\end{array}$ & $\begin{array}{l}\text { Consistency with other } \\
\text { communication }\end{array}$ & $\begin{array}{l}\text { Common starting points } \\
\text { for internal and external } \\
\text { communication, with } \\
\text { room for project partners }\end{array}$ & $\begin{array}{l}\text { Consistency with } \\
\text { other } \\
\text { communication }\end{array}$ \\
\hline Responsiveness & $\begin{array}{l}\text { Monitoring and } \\
\text { action based on } \\
\text { managing issues }\end{array}$ & $\begin{array}{l}\text { Monitoring and } \\
\text { action based on } \\
\text { feedback from } \\
\text { targeted media } \\
\text { sectors }\end{array}$ & $\begin{array}{l}\text { Communication } \\
\text { contributes to internal } \\
\text { views on external } \\
\text { changes and } \\
\text { communication skills } \\
\text { encourage internal } \\
\text { responsiveness }\end{array}$ & $\begin{array}{l}\text { Feedback is used to } \\
\text { develop communication } \\
\text { planning and activities }\end{array}$ & $\begin{array}{l}\text { Monitoring and } \\
\text { action based on } \\
\text { feedback from } \\
\text { professional sectors } \\
\text { across the EU }\end{array}$ \\
\hline $\begin{array}{l}\text { Effectiveness } \\
\text { and efficiency }\end{array}$ & $\begin{array}{l}\text { Assessment of } \\
\text { project reputation, } \\
\text { cost efficient } \\
\text { methods }\end{array}$ & $\begin{array}{l}\text { Assessment of cost } \\
\text { efficient methods }\end{array}$ & $\begin{array}{l}\text { Internal communication } \\
\text { audits, cost-efficient } \\
\text { methods }\end{array}$ & $\begin{array}{l}\text { Assessment of internal } \\
\text { and external } \\
\text { communication quality, } \\
\text { time management }\end{array}$ & $\begin{array}{l}\text { Assessment of } \\
\text { project processes } \\
\text { adoption across the } \\
\text { EU, cost efficient } \\
\text { methods }\end{array}$ \\
\hline
\end{tabular}

Table 2: GAP media evaluation tool; as an example of the proposed evaluation framework.

Measurement with the tool presented in Table 2 above is carried out as part of a quality cycle, the aim being to continuously improve the quality of the communication and its value for the organization (Vos, 2015; Juholin, 2010). Evaluation, according to Juholin (2010, p. 29), is an assessment of the value communication in its different forms produces, and how single actions benefit the organization. This chapter views projects as organizations created for a limited timeframe, and evaluation as a process, which aims at developing the activities of the project. Evaluation needs to be continuous and holistic, and based on the aims set for the project. Evaluations target planned activities, results achieved with these activities, objects for development, and needs for immediate action. The evaluation method and the measurements used must be defined, case-by-case, for the organization (Juholin, 2010, p. 30), or in this case, the project.

Section 5 discusses the experiences in the three projects ABC4EU, IECEU, and GAP, based on an analysis of the dissemination and communication plans of these three international projects. This chapter proposes an evaluation framework based on these experiences and illustrates the relevance of the framework by arguing that it fits the experiences gained in planning and coordinating dissemination activities in three EU funded projects.

\section{Results from the Three Projects}

The project ABC4EU Dissemination Plan (ABC4EU, 2014) stresses that all external communication and dissemination activities begin as soon as the project begins, and run throughout the project duration, with the aim of gaining project visibility. The plan outlines what will be communicated, who will do it, to whom, how, and why. Besides traditional methods for dissemination, such as press releases, newsletters, electronic publications, workshops, and conferences, the project aims at creating and growing its user network (end user community) in numbers, by using a secure online platform, an active end user community to disseminate relevant information of the project. "To ensure 
in Sarah Bowman, Adrian Crookes, Stefania Romenti, Øyvind Ihlen (ed.) Public Relations and the Power of Creativity (Advances in Public Relations and Communication Management, Volume 3, Emerald Publishing Limited, pp.197 - 214.

continuation for the work done in the project" (p. 9), this end user community is urged to live on and continue its active existence and cooperation even after the project has ended. The means of dissemination in project $\mathrm{ABC} 4 \mathrm{EU}$ are divided in: dissemination materials (the products created), and dissemination activities (the actions taken), and these are outlined in the ABC4EU Dissemination Plan (2014). Because the Framework Programme 7 did not have a requirement for media evaluation, the ABC4EU project did not evaluate its communication impacts in any other way than by listing and calculating its dissemination activities. For this purpose, there was a template and system of periodic reporting, and end user community reports.

The monitoring and evaluation indicators for IECEU were set early in the project, and later adapted, as the IECEU dissemination was evaluated to reach comprehensive visibility among its key stakeholders by use of different dissemination means, tools and activities (IECEU D8.1, 2015). The project was acknowledged by policymakers, academic and public audiences. The approach provided positive lessons for future projects in the external European safety and security domain. The engaging of key stakeholders in policy dialogues in various EU Member States was seen as a successful method of PR in terms of raising impact. The active use of technology selected in project dissemination activities by the partner organizations enhanced the information sharing towards end users and the general public. Moreover, social media polls and online meetings ensured the use of interactive methods when employing technology. In the final reporting phase, this was seen as key in terms of successful dissemination. IECEU engaged over 1,000 participants to actively follow only two social media channels, Twitter and Facebook.

The external communication and dissemination plan for GAP, Gaming for Peace (GAP D7.1, 2016) also looks for ways to "ensure efficient and sustainable information sharing in GAP even beyond the lifespan of the project" (p. 4). The GAP plan focuses on asking the questions: to whom to disseminate; where to disseminate? The plan is in line with the European Commission stressing the importance on clarifying messages based on the target audiences. These questions in the GAP plan guide all GAP dissemination actors to clearly focus their dissemination activities on the potential audiences for the results and products of the GAP project. Knowing how to identify these audiences can bring sustainability to the project. The Communications Plan for GAP lists key stakeholders for dissemination (GAP D7.1, 2016, pp.15-9).

GAP has a communication action matrix, which is built around milestones, work packages with partner responsibilities to communicate relevant actions, and deliverables that are related to each milestone. This is to ensure that all the partners of GAP are in a timely manner actively and fully carrying out the information sharing responsibilities that are expected of them. Building the relationships between the actors of the project's operational work packages and its external partners are based on these communication activities. It is important that all actors understand the values, which underline the communication practices of the GAP project. To create a GAP brand, the project partners need to share a clear vision. Thus, it is easier to form clear messages that communicate what GAP is, who its actors are, and why this project is important to society (GAP D7.2, 2016).

GAP's project documentation indicates that the division of work between internal and external communication is clear, with the coordinator being responsible for internal communication, and Laurea UAS for external communication, although external communication activities require approval by the coordinator before communication can take place. External communication and dissemination activities are also the responsibility of each beneficiary in addition to a work division table of responsibilities.

The media evaluation framework adapted for GAP takes the GAP Communications Plan, Grant Agreement and template for reporting of dissemination activities into consideration. The Communications Plan includes a table of both quantitative and qualitative questions to be used for 
in Sarah Bowman, Adrian Crookes, Stefania Romenti, Øyvind Ihlen (ed.) Public Relations and the Power of Creativity (Advances in Public Relations and Communication Management, Volume 3, Emerald Publishing Limited, pp.197 - 214.

the scientific analysis of external communication and dissemination in the project. The required scientific analysis has so far not been possible to carry out because not all the partners have delivered their periodic reporting of external communication and dissemination activities.

The evaluation tool adapted for the media evaluation can, in the future, be utilized as a selfassessment tool, thus, including the qualitative approach to evaluation by the active actors and communicators themselves. This enables the emphasis of accountability and the generating of selfdevelopment of the communication and dissemination activities of each project partner (beneficiary). Accountability for communication refers to taking responsibility for the communication strategy and the choices that are made, and how these contribute to the objectives of the project (Vos, 2015). Accountability is examined here on the level of the communication work package and the communication performance of the project as a whole.

All three projects implemented their dissemination and communication activities with people who mainly had knowledge and competence of the substance areas of research and development (e.g. security). Only few communication and PR professionals participated in project dissemination. This result was unexpected, since the dissemination objectives in EU funded projects are strongly related to deep competences and experiences of management of dissemination and PR. It was, however, recognized that the co-creative collaboration between professionals, researchers and developers, as well as the feedback and learning provided by evaluation, supported the reach of dissemination objectives.

\section{Tentative Conclusions and Implications}

The experiences in the three projects suggest that it is important that partners agree to jointly cooperate on external communication and dissemination activities, and to understand how vital these activities are for the success of the project. These actions are PR for the project, and thus the project should include PR professionals to develop PR skills of its actors. Next, commitment and active participation of partners and end user groups in the early stage of the project implementation is key to increase the impact of the project results and finally, meet with the project's dissemination goals. Moreover, dissemination in international research and development projects should be an ongoing process. The process should start when the project begins, and last until the end of the project. Ideally, the dissemination process begins with the project proposal and extends to the sustainability of the project stakeholder community, even after the project has terminated or not received funding. The benefit of networks may bring added value for partners in the future.

Additionally, it can be noted that dissemination is an expanding process. Figure 1 shows this expansion of the User Community from year one (Y1) to year three (Y3), a growing number of stakeholders (end users, industry, NGOs, authorities, academia, etc.) participating in the communication within the community. A small nucleus in the beginning of the project leads to growing numbers of stakeholders actively being targeted and participating in the co-creation of the dissemination process. Also, key target audiences should be clarified, followed, and updated throughout the project lifespan. The selection of communication channels should be amended based on this clarification process. The target audience will most likely expand in not only number, but also to include a wider range of stakeholders by the end of the project, and after.

In the project IECEU, easily measurable indicators (IECEU D8.1, 2015) were set at an early stage to monitor the success of dissemination by IECEU. The monitoring process includes quantitative monitoring and evaluation indicators. Measuring the objectives throughout the project identified both gaps and trends to make sure that the project was going to a desired direction and provided valuable information to further improve the communication activities. Results from the first media evaluation 
in Sarah Bowman, Adrian Crookes, Stefania Romenti, Øyvind Ihlen (ed.) Public Relations and the Power of Creativity (Advances in Public Relations and Communication Management, Volume 3, Emerald Publishing Limited, pp.197 - 214.

in GAP indicate that not all partners have yet realized the potential and benefits of actions promoting strategic communication of the project. Furthermore, there is little cooperation between partners as the cooperation is regulated by the contract and enacted by the project coordinator. However, as the project has only recently started, there are many options to develop the activities even together. The key to such co-creative work lies in the will to work as a team. Therefore, PR skills become more and more important for projects to meet requirements set by the EU for the external communication and dissemination of research and innovation projects. The use of selected technology for PR, dissemination and communication, presents a new type of competence challenges and opportunities for professionals and experts.

Instruments for public funding of research and innovation projects call for open dissemination of project results. However, the EU does not demand two-way communication in these activities, which clearly would be the way to generate better results and engage different audiences. Perhaps the EU could develop their visions of external communication and dissemination in the era of digital communication and community-based cooperation. When communication and dissemination activities begin early enough, for example right at the start of the project, and expand the stakeholder community, the project and its results become wider known. It is in the interest of the European Commission that as many end users as possible adopt new innovations, which in turn will generate more business possibilities for the industry, and further research projects for the academia.

Ideally the project's end user communities may find sustainability that outlasts the project. Project partners could engage end user communities in collaborative PR activities to engage the end users during the project. This creates opportunities for spontaneous cooperation and further the co-creation of innovations, products, and services, not to mention new development projects. PR professionals have a strategic opportunity in facilitating activities within the proposed model of co-creation in the EU funded projects context. The potentials in using technology in dissemination and communication of international research and innovation projects are highly recommended to be further studied while enhancing professionalism.

\section{Acknowledgements:}

The research leading to these results has received funding from the European Community's Framework 7 Programme for ABC4EU - ABC Gates for Europe, and the European Community's Horizon 2020 Programme for IECEU - Improving the Effectiveness of Capabilities in EU conflict prevention and GAP - Gaming for Peace.

\section{References:}

ABC4EU - ABC Gates for Europe (2012). ABC gates for Europe Proposal, SEC-2012.3.4-6 Enhancing the workflow and functionalities of Automated Border Control (ABC) gates -Integration Project

ABC4EU - ABC Gates for Europe (2014). Dissemination Plan, Project deliverable D 7.7 M3, 9.4.2014.

Allen, S., Bailetti, T., and Tanev, S. (2009). Components of Co-Creation, The Open Source Business Resource, November 2009. 
in Sarah Bowman, Adrian Crookes, Stefania Romenti, Øyvind Ihlen (ed.) Public Relations and the Power of Creativity (Advances in Public Relations and Communication Management, Volume 3, Emerald Publishing Limited, pp.197 - 214.

Davis Cross, M.K., (2015). The Limits of Epistemic Communities: EU Security Agencies, Politics and Governance, Volume 3, Number 1.

Di Cagno, D., Fabrizi, A., and Meliciani, V. (2014). The impact of participation in European joint research projects on knowledge creation and economic growth, Journal of Technology Transfer, Vol. 39, 6, 836-858.

Falkheimer, J. \& Heide, M. (2014). From Public Relations to Strategic Communication in Sweden: The Emergence of a Transboundary Field of Knowledge, Nordicom Review, 35(2), 123-138.

European Commission (2011). Cooperation, Work Programme 2012, Theme 10, Security, European Commission C(2011)5068, 19 July 2011.

European Commission (2014). Horizon 2020, Communicating EU research and innovation guidance for project participants, Version 1.0, 25 September 2014.

European Commission (2016). Webpage: What is the difference between dissemination, exploitation and communication? Research and Innovation. Participant Portal, available at: https://ec.europa.eu/research/participants/portal/desktop/en/support/faqs/faq-933.html (accessed 25 May 2017).

European Commission (2017). Webpage: European Commission, Research \& Innovation, Participant Portal, support, available at:

https://ec.europa.eu/research/participants/portal/desktop/en/support/faqs/faq-933.html (accessed 25 May 2017)

European IPR Fact Sheet (2014). The Plan for the Exploitation and Dissemination of Results in Horizon 2020, European IPR Helpdesk, available at: https://www.iprhelpdesk.eu/.

Falkheimer, J. \& Heide, M. (2014). From Public Relations to Strategic Communication in Sweden: The Emergence of a Transboundary Field of Knowledge, Nordicom Review, 35(2), 123-138.

Frow, P., Nenonen, S., Payne, A., and Storbacka, K. (2015). Managing Co-creation Design: A Strategic Approach to Innovation, British Journal of Management, Vol. 26(3), 463.

GAP - Gaming for Peace (2016). D7.1 Communications Plan, available at: 1.9.2016. http://gapproject.eu/publications/deliverables/ (accessed 25 May 2017)

GAP - Gaming for Peace (2016). D7.2 Communications Package, available at: 1.9.2016. http://gapproject.eu/publications/deliverables/ (accessed 25 May 2017)

Hyttinen, K. (2017). Project Management Handbook. Laurea Publications 76, Laurea University of Applied Sciences. ISBN: 978-951-799-452-1. 
in Sarah Bowman, Adrian Crookes, Stefania Romenti, Øyvind Ihlen (ed.) Public Relations and the Power of Creativity (Advances in Public Relations and Communication Management, Volume 3, Emerald Publishing Limited, pp.197 - 214.

IECEU - Improving the Effectiveness of Capabilities (IEC) in EU conflict prevention (2015). 8.1 Dissemination Plan PU IECEU CSA project: 653371 Start date: 01/05/2015, available at: http://www.ieceu-project.com/wp-content/uploads/2016/12/D8.1-Dissemination-Plan-PU.pdf (accessed 5 July 2017)

Juan, A et al. 2012. Collaborative and Distributed E-Research: Innovations in Technologies, Strategies and Applications: Innovations in Technologies, Strategies and Applications. IGI Global. ISBN13: 9781466601253.

Juholin, Elisa. Arvioi ja paranna. Viestinnän mittaamisen opas. Vantaa: Infor Oy, 2010.

Laurea University of Applied Sciences (2011). Learning by Developing. LbD Guide, available at: https://www.laurea.fi/en/document/Documents/LbD_Guide_04102011_ENG.pdf\#search=lbd\%20g uide (accessed 5 July 2017).

Palttala, P., \& Vos, M. (2012). Quality Indicators for Crisis Communication to Support Emergency Management by Public Authorities. Journal of Contingencies and Crisis Management, 20(1), 3951.

Pirinen,R. (2015). Studies of Externally Funded Research and Development Projects in Higher Education: Knowledge Sources and Transfers, Creative Education, 2015, 6, 3, 315-330.

Ruoslahti, H. (2017). Co-creation of Knowledge for Innovation and Multi-Stakeholder Participation of End Users: A Structured Literature Review, paper submitted to EUPRERA 2017, London, October $12-14.2017$.

Sriramesh, K. Štumberger, N. (2017). Globalization and Public Relations, In: Global Encyclopedia of Public Administration, Public Policy, and Governance, A. Farazmand (ed.), Springer International Publishing AG 2017.

Verčič, D, Zerfass, A, Wiesenberg, M (2015). Global public relations and communication management: a European perspective. Public Relations Review 41(5): 785-793.

Vos M. (2015). Communication Health Check - Measuring Corporate Communication Performance, Journal of Business Studies Quarterly 2015, Volume 7, Number 1.

Vos \& Schoemaker (2004). Accountability of Communication Management, A Balanced Scorecard for Communication Quality, Lemma Publishers, Utrecht, 2004.

Vos, M., \& Schoemaker, H. (2011). Integrated Communication: Concern, Internal and Marketing communication. Amsterdam: Eleven Publishing.

Wilson, P. M., Petticrew, M., Calnan, M. W., \& Nazareth, I. (2010). Disseminating research findings: What should researchers do? A systematic scoping review of conceptual frameworks. Implementation Science, 5, 91. 